From the Departments of Epidemiology and Radiotherapy and Division of Experimental Therapy, the Netherlands Cancer Institute; Department of Hematology, Vrije Universiteit Medical Center; Department of Paediatric Oncology, Emma Children's Hospital/ Academic Medical Center, University of Amsterdam, Amsterdam; Department of Epidemiology and Biostatistics, Radboud University Nijmegen Medical Center, Nijmegen; Departments of Hematology and Radiotherapy, Erasmus MC, Daniel den Hoed Cancer Center, Rotterdam; Department of Radiotherapy, Leiden University Medical Center, Leiden; and the Eindhoven Cancer Registry, Comprehensive Cancer Center South, Eindhoven, the Netherlands.

Submitted September 5, 2008: accepted March 20, 2009; published online ahead of print at www.jco.org on August 10, 2009

Supported by Grants No. NKI 98-1833 and NKI 04-3068 from the Dutch Cancer Society, Amsterdam, the Netherlands.

Authors' disclosures of potential conflicts of interest and author contributions are found at the end of this article.

Corresponding author: Flora E. van Leeuwen, PhD, Department of Epidemiology, the Netherlands Cancer Institute, Plesmanlaan 121, $1066 \mathrm{CX}$ Amsterdam, the Netherlands; e-mail:

F.v.Leeuwen@nki.nl.

The Acknowledgment is included in the full-text version of this article, available online at www.jco.org. It is not included in the PDF version (via Adobe® Reader ${ }^{\circledR}$ )

() 2009 by American Society of Clinical Oncology

0732-183X/09/2726-4239/\$20.00

DOI: 10.1200/JCO.2008.19.9174

\title{
Breast Cancer Risk in Female Survivors of Hodgkin's Lymphoma: Lower Risk After Smaller Radiation Volumes
}

Marie L. De Bruin, Judith Sparidans, Mars B. van't Veer, Evert M. Noordijk, Marieke W.J. Louwman, Josée M. Zijlstra, Hendrik van den Berg, Nicola S. Russell, Annegien Broeks, Margreet H.A. Baaijens, Berthe M.P. Aleman, and Flora E. van Leeuwen

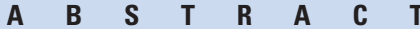

\section{Purpose}

We assessed the long-term risk of breast cancer $(B C)$ after treatment for Hodgkin's lymphoma $(\mathrm{HL})$. We focused on the volume of breast tissue exposed to radiation and the influence of gonadotoxic chemotherapy (CT).

\section{Patients and Methods}

We performed a cohort study among 1,122 female 5-year survivors treated for HL before the age of 51 years between 1965 and 1995. We compared the incidence of BC with that in the general population. To assess the risk according to radiation volume and hormone factors, we performed multivariate Cox regression analyses.

\section{Results}

After a median follow-up of 17.8 years, 120 women developed BC (standardized incidence ratio [SIR], 5.6; 95\% Cl, 4.6 to 6.8), absolute excess risk 57 per 10,000 patients per year. The overall cumulative incidence 30 years after treatment was $19 \%(95 \% \mathrm{Cl}, 16 \%$ to $23 \%)$; for those treated before age 21 years, it was 26\% (95\% Cl, 19\% to 33\%). The relative risk remained high after prolonged follow-up (>30 years after treatment: SIR, 9.5; 95\% Cl, 4.9 to 16.6). Mantle field irradiation (involving the axillary, mediastinal, and neck nodes) was associated with a 2.7-fold increased risk $(95 \% \mathrm{Cl}, 1.1$ to 6.9 ) compared with similarly dosed (36 to $44 \mathrm{~Gy}$ ) mediastinal irradiation alone. Women with $\geq 20$ years of intact ovarian function after radiotherapy at young ages ( $<31$ years) experienced significantly higher risks for BC than those with fewer than 10 years of intact ovarian function.

\section{Conclusion}

Reduction of radiation volume appears to decrease the risk for BC after HL. In addition, shorter duration of intact ovarian function after irradiation is associated with a significant reduction of the risk for $\mathrm{BC}$.

\section{J Clin Oncol 27:4239-4246. (C) 2009 by American Society of Clinical Oncology}

\section{INTRODUCTION}

The strongly elevated risk of breast cancer (BC) after radiotherapy for Hodgkin's lymphoma (HL) has become a major concern for female survivors of this disease. ${ }^{1-7}$ Studies performed so far show an increased risk for $\mathrm{BC}$ up to 30 years after treatment, and a stronger risk increase in women who received radiation at young ages. ${ }^{2,8-10}$ Few studies have been able to estimate the risk in long-term survivors with a follow-up of 30 years or longer.

The risk of BC after HL has been mainly attributed to supradiaphragmatic radiotherapy (RT). Women treated with mantle field radiation experience up to 30-fold increased risks for BC compared with their peers in the general population. ${ }^{11}$ Doseresponse relationships have been shown for the ra- diation dose to the area of the breast where the tumor developed. ${ }^{12,13}$ However, an important issue which has been hardly addressed involves the volume of breast tissue exposed to radiation and its effect on risk of BC. ${ }^{14-16}$ In female HL survivors treated before age 41, treatment with gonadotoxic alkylating chemotherapy (CT) as well as pelvic RT have been shown to reduce the risk of radiationinduced $\mathrm{BC}$, which was attributed to premature menopause. ${ }^{12,13}$ In female survivors of childhood HL, however, this protective effect of alkylating CT was not evident, whereas the effect of pelvic RT was. ${ }^{8,17}$ Consequently, the hypothesis of risk reduction by therapy-induced menopause is still controversial.

The aim of this study was to assess the risk of BC as a second malignancy after treatment for HL over a 


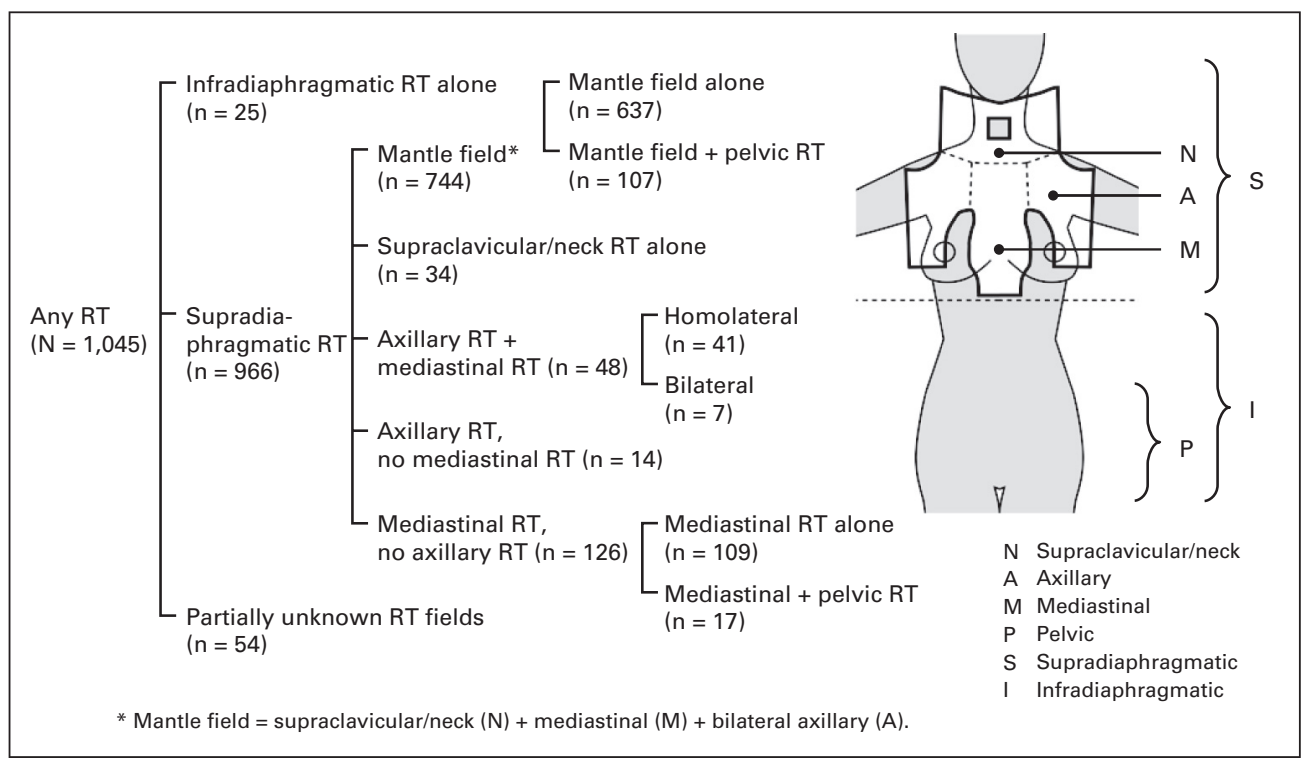

Fig 1. Applied radiation-fields in study population $(n=1,122)$

broad range of ages at treatment and calendar years. Unique features of our study include long-term and near complete follow-up and the availability of detailed information on treatment as well as risk factors for a large cohort. We focused on supradiaphragmatic radiation volume and assessed the role of gonadotoxic CT and RT on the risk of BC after HL.

\section{PATIENTS AND METHODS}

\section{Data Collection Procedures}

We performed a cohort study in all women who had been treated for HL at five cancer centers/university hospitals in the Netherlands (the Netherlands Cancer Institute-Antoni van Leeuwenhoek Hospital [NKI/AVL] in Amsterdam, Erasmus MC/Daniel den Hoed Kliniek [EMC/DdHK] in Rotterdam, Vrije Universiteit Medical Center [VUMC] in Amsterdam, Leiden University Medical Center [LUMC] in Leiden, the Emma Children's hospital/Academic Medical Center [EKZ] in Amsterdam) and in hospitals in the region of the Eindhoven Cancer Registry (IKZ). Patient selection and methods of data collection in NKI/AVL and EMC/DdHK have been described in detail previously ${ }^{5,18-21}$; in the other centers methods were comparable. Patients were younger than 51 years at treatment for HL (1965 to 1995) with either RT and/or CT and survived at least 5 years. Data were collected directly from the medical records and, in case the information could not be obtained from the medical record, from questionnaires sent to general practitioners and attending physicians. We succeeded in obtaining medical status up to at least January 1, 2002 for 1,060 women (94\%). Information was collected on birth date, date of treatment, treatment modality (primary + salvage), date of last medical contact or date of death, date of diagnosis of BC, localization and morphology of $\mathrm{BC}$, and the occurrence of other second malignancies. Pathology reports were reviewed to verify all $\mathrm{BC}$ diagnoses.

For all women treated in NKI/AVL, EMC/DdHK, LUM,C or EKZ $(\mathrm{n}=973)$, additional risk factors were recorded (weight, height, and smoking at diagnosis and end of follow-up, age at menarche [for those treated before age 15], menopausal status at end of follow-up, age at menopause [absence of menstrual periods for more than 12 months], parity, ever use of oral contraceptives [OC], and hormone replacement therapy [HRT]). A subset of women $(256$ of 1,122$)$ participated in a case-control study and filled out a questionnaire providing information on hormone and lifestyle factors. ${ }^{13}$ We used the questionnaires for information on hormone and lifestyle factors if the information was not present in the medical records.
Of the 1,131 5-year survivors identified, nine were excluded because they were treated with RT or CT for another malignancy before or within the first 5 years after the start of treatment for HL, leaving 1,122 patients eligible for analyses.

\section{Outcome Definition}

Patients were defined as cohort members who developed BC 5 years or more after first treatment for HL. BC was defined as any malignant or in situ tumor classified as code 174 according to the International Classification of Diseases, ninth edition (ICD-9). We differentiated between ductal carcinoma in situ (DCIS) and invasive BC (IBC). Lobular carcinoma in situ was excluded.

\section{Treatment}

We recorded detailed information on RT fields, chemotherapeutic agents, and number of cycles. Approximately one third of the patients was treated in European Organisation for Research and Treatment of Cancer (EORTC) protocols. ${ }^{22}$ The distribution of RT fields, based on primary as well as salvage treatment, is given in Figure 1. RT techniques have changed over the years. In the 1960s, patients were treated with cobalt-60 or orthovoltage therapy; from the 1970s onward, linear accelerators were used (usually $8 \mathrm{MV}$ photons). Individual blocks were used to shield normal tissues as much as possible. In addition, most patients were treated with one field per day only. Patients usually received $40 \mathrm{~Gy}$ ( 36 to $44 \mathrm{~Gy}$ ) in fractions of $2.0 \mathrm{~Gy}$. Information on radiation doses and fractionation schedules for individual patients was not collected. Mantle field irradiation was the most commonly applied radiation field from the early 1970s to the late 1980s. Since the late 1980s, a growing number of patients received more limited radiation fields (involved field irradiation). It was not until the late 1990s, however, that elective mantle field after chemotherapy was abandoned. ${ }^{22-24}$ In our cohort, limited supradiaphragmatic radiation fields were applied during all treatment periods $(33 \%$ before $1975,17 \%$ from 1975 to $1987,50 \%$ from 1988 to 1995). The majority of patients treated with mediastinal irradiation (154 of 188) also received supraclavicular/neck irradiation.

Cumulative procarbazine dose was used as a measure for gonadotoxicity for alkylating CT. ${ }^{21}$ A cumulative dose of $8.4 \mathrm{~g} / \mathrm{m}^{2}$ is equivalent to 6 cycles of mechlorethamine, vincristine, procarbazine, and prednisone (MOPP) or 12 cycles of MOPP/doxorubicine, bleomycine, and vinblastine ( $\mathrm{ABV}$ ).

\section{Statistical Analysis}

Follow-up started 5 years after first treatment for HL and ended at date of diagnosis of BC or any other second malignancy treated with RT and/or CT, date of death, or date of most recent medical information, whichever came first. BC occurring as a third malignancy, after a second malignancy treated with RT and/or CT, was therefore excluded. 


\begin{tabular}{|c|c|c|c|}
\hline \multirow[b]{2}{*}{ Characteristic } & \multicolumn{2}{|c|}{ HL Patients } & \multirow[b]{2}{*}{ Events } \\
\hline & No. & $\%$ & \\
\hline No. of patients & 1,122 & & $120^{*}$ \\
\hline \multicolumn{4}{|l|}{ Hospital } \\
\hline NKI/AVL & 355 & 31.6 & 53 \\
\hline EMC/DdHK & 401 & 35.7 & 38 \\
\hline LUMC & 188 & 16.8 & 18 \\
\hline IKZ & 115 & 10.2 & 7 \\
\hline VUMC & 34 & 3.0 & 4 \\
\hline EKZ & 29 & 2.6 & 0 \\
\hline \multicolumn{4}{|l|}{ Age at first treatment of $\mathrm{HL}$, years } \\
\hline$\leq 20 \dagger$ & 311 & 27.7 & 42 \\
\hline $21-30$ & 426 & 38.0 & 48 \\
\hline $31-40$ & 264 & 23.5 & 24 \\
\hline $41-50$ & 121 & 10.8 & 6 \\
\hline \multicolumn{4}{|l|}{ Year of first treatment } \\
\hline $1965-1975$ & 331 & 29.5 & 48 \\
\hline 1975-1985 & 381 & 34.0 & 49 \\
\hline $1985-1995$ & 410 & 36.5 & 23 \\
\hline \multicolumn{4}{|l|}{ Maximum follow-up interval, years } \\
\hline $5-9$ & 1,122 & 100 & 7 \\
\hline $10-14$ & 979 & 87.3 & 18 \\
\hline $15-19$ & 699 & 62.3 & 34 \\
\hline $20-24$ & 449 & 40.0 & 26 \\
\hline $25-29$ & 244 & 21.7 & 23 \\
\hline$\geq 30$ & 122 & 10.9 & 12 \\
\hline \multicolumn{4}{|l|}{ Treatment category } \\
\hline RT only & 357 & 31.8 & 70 \\
\hline CT only & 80 & 7.1 & 0 \\
\hline $\mathrm{RT}+\mathrm{CT}$ & 685 & 61.1 & 50 \\
\hline \multicolumn{4}{|l|}{ Radiation fields } \\
\hline Mediastinal RT & 126 & 11.2 & 7 \\
\hline Axillary RT ( \pm mediastinum) & 62 & 5.5 & 3 \\
\hline Mantle field & 744 & 66.3 & 109 \\
\hline Pelvic RT & 161 & 14.3 & 6 \\
\hline \multicolumn{4}{|l|}{ Chemotherapy } \\
\hline No CT/non-alkylating CT & 424 & 37.8 & 80 \\
\hline Alkylating $\mathrm{CT}, \leq 8.4 \mathrm{~g} / \mathrm{m}^{2}$ procarbazine & 358 & 31.9 & 27 \\
\hline Alkylating $\mathrm{CT},>8.4 \mathrm{~g} / \mathrm{m}^{2}$ procarbazine & 123 & 11.0 & 6 \\
\hline \multicolumn{4}{|l|}{$\mathrm{CT}$ and $\mathrm{RT}$} \\
\hline Supradiaphragmatic RT + MOPP & 160 & 14.3 & 13 \\
\hline Supradiaphragmatic RT + MOPP/ABV & 129 & 11.5 & 9 \\
\hline $\begin{array}{l}\text { Supradiaphragmatic RT + MOPP + } \\
\text { other alkylating CT }\end{array}$ & 134 & 11.9 & 9 \\
\hline $\begin{array}{l}\text { Supradiaphragmatic RT + other } \\
\text { alkylating CT }\end{array}$ & 131 & 11.7 & 4 \\
\hline $\begin{array}{l}\text { Supradiaphragmatic RT + non- } \\
\text { alkylating CT }\end{array}$ & 45 & 4.0 & 11 \\
\hline $\begin{array}{l}\text { Supradiaphragmatic } \mathrm{RT}+\mathrm{CT} \text {, agents } \\
\text { unknown }\end{array}$ & 41 & 3.7 & 3 \\
\hline \multicolumn{4}{|l|}{ Premature menopause } \\
\hline Menopause at age 41 or later & 298 & 26.6 & 54 \\
\hline Menopause before age 41 & 214 & 19.1 & 14 \\
\hline Age $\leq 41$ at end of follow-up & 191 & 17.0 & 19 \\
\hline \multicolumn{4}{|l|}{ Years intact ovarian function $\neq$} \\
\hline$<10$ & 261 & 23.2 & 20 \\
\hline $10-20$ & 248 & 22.1 & 35 \\
\hline$>20$ & 124 & 11.1 & 32 \\
\hline \multicolumn{4}{|l|}{ Lifestyle factors§ } \\
\hline Smoking & 232 & 20.7 & 19 \\
\hline $\mathrm{BMI}>30$ & 248 & 22.1 & 32 \\
\hline \multicolumn{4}{|c|}{ (continued in next column) } \\
\hline
\end{tabular}

\begin{tabular}{|c|c|c|c|}
\hline \multirow[b]{2}{*}{ Characteristic } & \multicolumn{2}{|c|}{ HL Patients } & \multirow[b]{2}{*}{ Events } \\
\hline & No. & $\%$ & \\
\hline \multicolumn{4}{|l|}{ Hormone factors } \\
\hline Nulliparity & 527 & 47.0 & 43 \\
\hline Oral contraceptive use & 565 & 50.4 & 79 \\
\hline \multicolumn{4}{|c|}{ 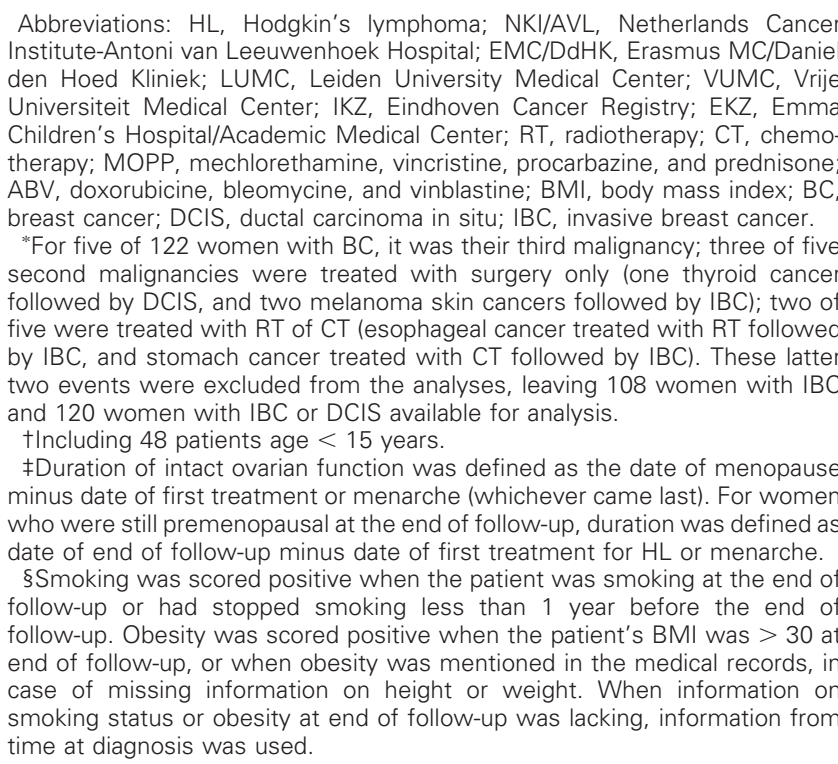 } \\
\hline
\end{tabular}

We calculated the cumulative incidence of BC (IBC and DCIS together) with death as a competing risk, ${ }^{25}$ and compared it with the actuarial risk of BC using the Kaplan-Meier method. ${ }^{26}$

We compared the incidence of IBC in our cohort with that in the general population, using incidence rates from the Eindhoven Cancer Registry ${ }^{27}$ up to 1988 and from the Netherlands Cancer Registry ${ }^{28}$ for the period 1989 to 2003. We calculated standardized incidence ratios (SIRs) and absolute excess rates (AERs), taking into account person-years of the patients in the HL cohort, according to methods previously described. ${ }^{5}$ We excluded DCIS in these analyses, because reference rates from the general population were not available. Population-expected risks were calculated according to Hakulinen's method. ${ }^{29}$

To study the association between radiation volume and risk of $\mathrm{BC}$, taking into account several covariates, we performed multivariate Cox regression analyses. ${ }^{30}$ We selected all women treated with mantle field, axillary, or mediastinal irradiation (with or without chemotherapy) before age $41(n=782)$. In this subgroup, we modeled the risk of radiation volume taking into account pelvic RT and cumulative procarbazine dose (model 1), pelvic RT and CT regimen (model 2), age at menopause, lifestyle and hormone factors (model 3 ), and years of intact ovarian function, lifestyle and hormone factors (model 4). For models 3 and 4 , information on covariates was present only in four hospitals (NKI/AVL, EMC/DdHK, LUMC, and EKZ, $\mathrm{n}=715$ ).

Awareness of physicians and patients with respect to BC after HL has increased over time, as well as diagnostic techniques and screening policies. These factors may have influenced early detection of $\mathrm{BC}$ over time. We therefore used calendar time during follow-up as the time scale in our analyses, ${ }^{31}$ and adjusted for time since diagnosis and age. IBC and DCIS were used as a combined end point, and treatment-related variables as well as cumulative duration of intact ovarian function were time-dependent. All analyses were performed using S-plus (version 3.3; Statistical Sciences, Seattle, WA) statistical software (Insightful Corporation, Seattle, WA, USA), and SAS 9.1 (SAS Institute Inc, Cary, NC). 


\section{RESULTS}

During follow-up, 122 of 1,122 female 5-year survivors of HL developed BC. All of them had previously received RT. Of the 122 women, 13 had multiple events (eight bilateral IBC, five IBC and DCIS), 12 developed DCIS and the remaining 97 developed IBC. Two IBC events were excluded, because they occurred after another RT/CTtreated second malignancy (Table 1), leaving 108 women with IBC and 120 women with IBC or DCIS available for analyses. The median follow-up time for the total cohort was 17.8 years (range, 5 to 40 years). Median age of the cohort members at first treatment for HL was 26.3 years (range, 5 to 50 years). The cumulative risk (Kaplan-Meier) for BC 30 years after first treatment was 25\% (95\% CI, 20\% to 30\%), whereas the cumulative incidence accounting for death as a competing risk was $19 \%(95 \% \mathrm{CI}, 16 \%$ to $23 \%$ ) at that time (Fig 2A). The cumulative incidence increased with decreasing age at first treatment for HL (Fig 2B; log-rank $P, .04$ ). The cumulative incidence in the youngest group (treated before age 21 years) 30 years after treatment was as high as $26 \%$ (95\% CI, 19\% to $33 \%$ ), with an attained age of 51 years or younger at that time.

Compared with the general population (Tables 2 and 3), women treated for HL experienced a 5.6-fold increased risk for IBC (SIR, 5.6; 95\% CI, 4.6 to 6.8 ; AER, 57 cases per 10,000 persons per year; $95 \%$ CI, 45 to 72 ). Significantly elevated risks were noted for women younger than 40 years at first treatment for HL, but not for women treated between ages 41 and 50. There was a significant trend of increasing SIRs with younger age at first treatment $(P<.0001)$. The SIRs of the whole cohort significantly increased with duration of follow-up $(P$ for trend, $<.0001)$. There was no marked decrease of the risk in the longest follow-up period. When considering changes in risk over time according to age at first treatment, the SIRs of women treated before age 21 and between ages 21 to 30 did not change with longer follow-up ( $P=.36$ and $P=.19$, respectively), whereas the SIRs significantly increased among women treated between ages 31 and $40(P=.005)$. The number of observed cases among women treated between 41 and 50 was rather small, but no trends were apparent.

Among patients treated with mantle field irradiation (without pelvic RT), the incidence of IBC was 8 times higher than in the general population (SIR, 8.2; 95\% CI, 6.6 to 10.1 ). Patients treated with mediastinal irradiation alone or pelvic irradiation in addition to mantle field irradiation had substantially lower risks (Fig 2C). The differences in SIRs may partially be explained by differences in follow-up time. The multivariate Cox regression analyses (Tables 4 and 5), in which time-to-event is taken into account, however, also revealed that women treated with mantle field irradiation experienced an almost three-fold increased risk for BC compared with those treated with mediastinal irradiation alone (Table 4 , models 1 to 4 ). Women who received pelvic RT experienced nonsignificantly lower risks for BC (model 1: $P=.15$; model 2: $P=.13$ ). Alkylating CT also seemed to reduce the risk for $\mathrm{BC}$ among women treated with mantle field or mediastinal irradiation, but no clear dose-response relationships (Table 4, models 1 and 2). No effects of smoking, obesity, nulliparity, or oral contraceptive use on BC risk were identified (Table 4, model 4).

With regard to the effect of fertile lifespan after irradiation to the breast, we observed strong effects of premature menopause and the duration of intact ovarian function after RT, both in women treated before age 21, and among those treated between ages 21 and 30 (Table

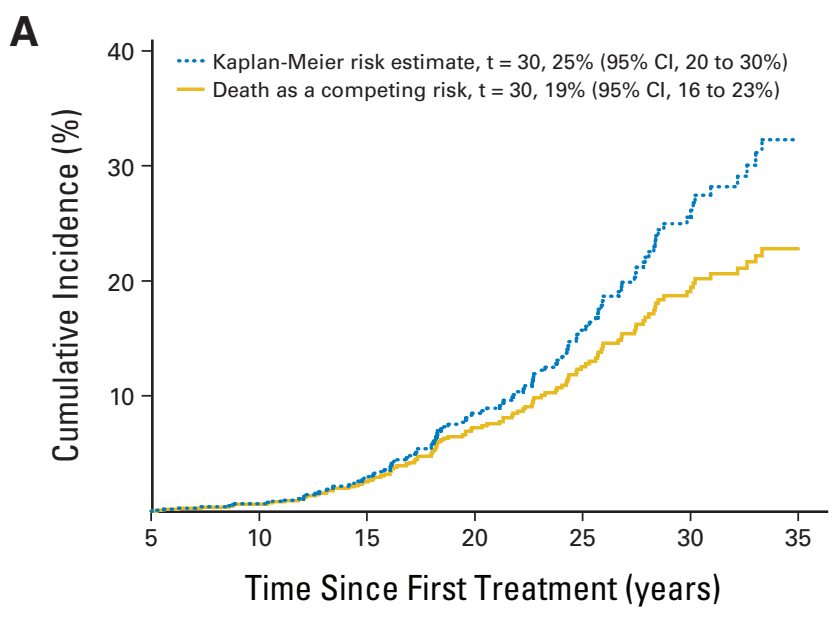

$\begin{array}{lllllll}\text { No. at risk } 1,122 & 980 & 700 & 450 & 245 & 123 & 29\end{array}$

B
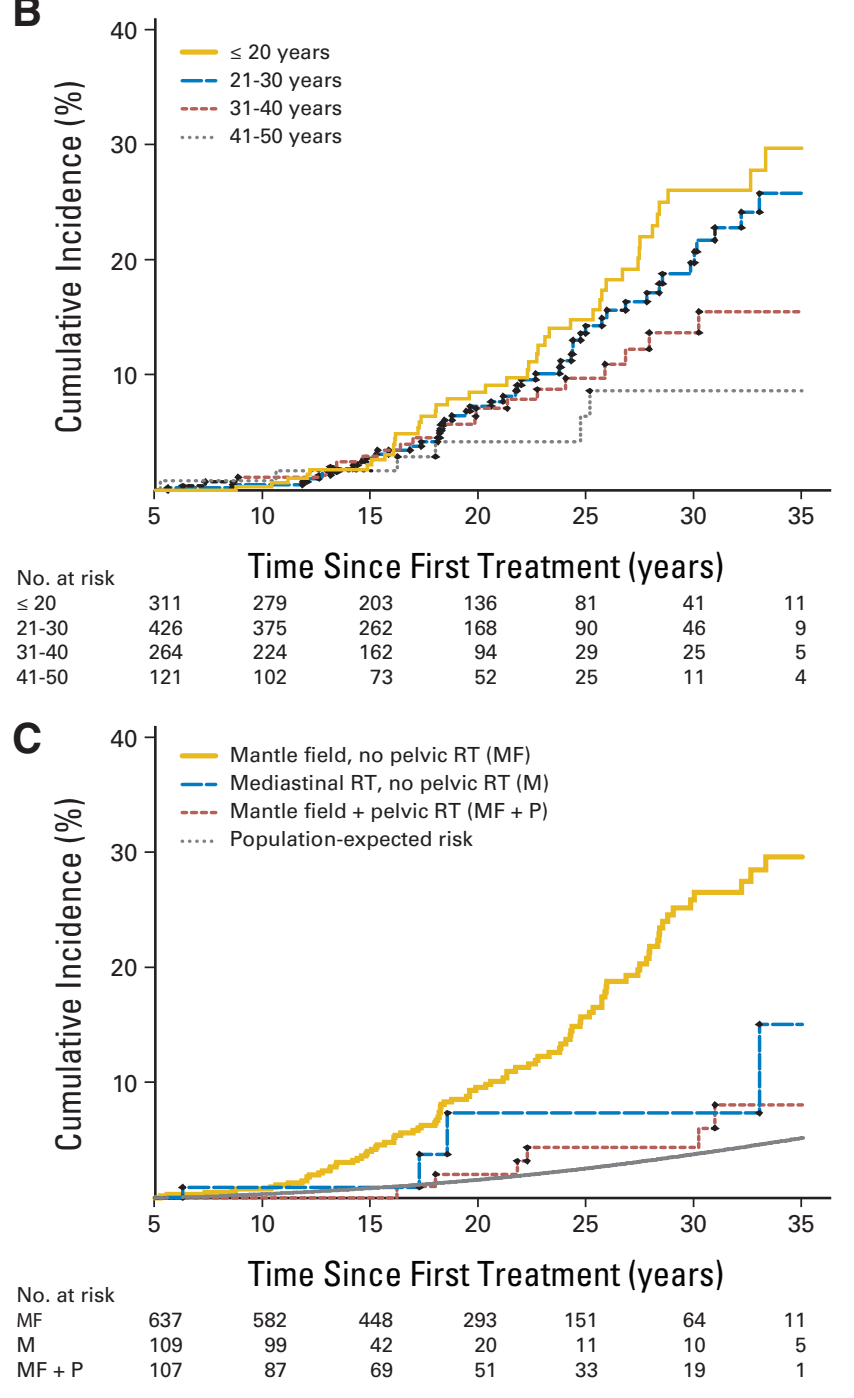

Fig 2. The cumulative incidence of breast cancer $(B C)$ after Hodgkin's lymphoma. (A) Cumulative risk and incidence of $B C$ (invasive $B C$ [IBC] + ductal carcinoma in situ [DCIS]). (B) Cumulative incidence of $\mathrm{BC}$ (IBC + DCIS) according to age at first treatment. (C) Cumulative incidence of IBC according to radiation fields and population-expected risk. 
Table 2. SIRs and Absolute Excess Risks of IBC, According to Age at First Treatment for HL, Follow-Up Interval, Treatment Period, and Radiation Field

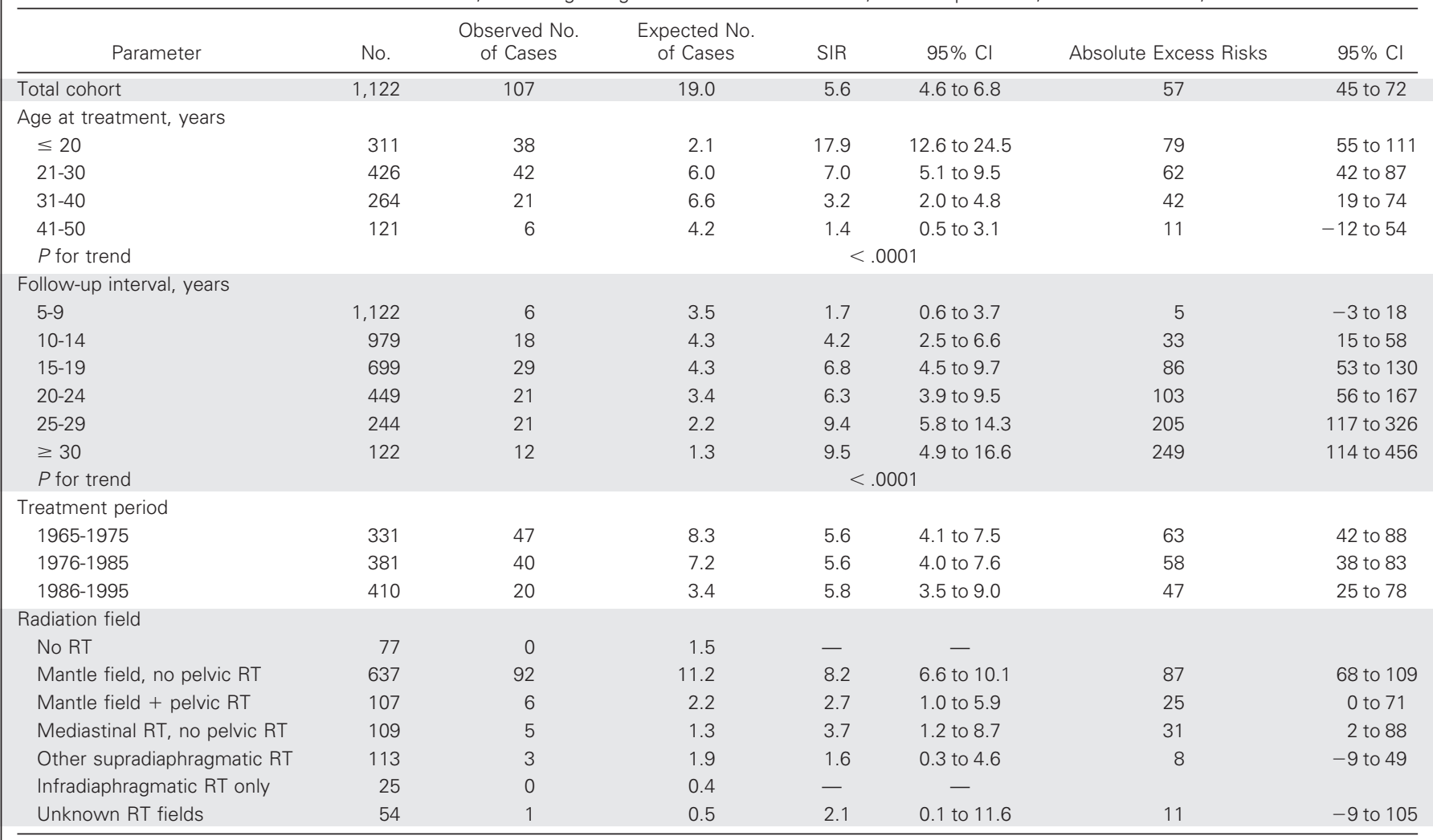

Abbreviations: SIR, standardized incidence ratio; IBC, invasive breast cancer; HL, Hodgkin's lymphoma; RT, radiotherapy.

5, models 3 and 4). Among women treated between ages 31 and 40 cumulative exposure to endogenous estrogens was not associated with risk for BC (Table 5, model 4).

\section{DISCUSSION}

To our knowledge, this study is the first to reliably examine the risk of $\mathrm{BC}$ after HL according to radiation volume. Mantle field irradiation was associated with a 2.7-fold increased risk of BC compared with mediastinal irradiation alone. Our results support the hypothesis that reducing the proportion of breast tissue exposed to radiation will indeed decrease the future risk for $\mathrm{BC}$, the most important late treatment effect among female survivors of HL.
We examined the influence of supradiaphragmatic radiation volume in a time period when applied radiation doses were rather stable (approximately 36 to $44 \mathrm{~Gy}$ ). In addition, we controlled for calendar year period, to adjust for residual effects of dose reductions over time. We had the unique availability of detailed treatment information for a large group of patients treated in the 1960s, before mantle field techniques became the standard treatment, at a time when smaller radiation fields were still applied. Our results confirm findings from a meta-analysis of Hodgkin's trials by Franklin et $\mathrm{al}^{16}$ showing a relative risk of 3 comparing extended field RT with involved field RT. This is an important finding, since the meta-analysis suffered from incomplete follow-up which might have biased the results.

\begin{tabular}{|c|c|c|c|c|c|c|c|c|c|}
\hline \multirow[b]{2}{*}{$\begin{array}{c}\text { Age at Treatment } \\
\text { (years) }\end{array}$} & \multicolumn{3}{|c|}{ 5-14 Year Follow-Up } & \multicolumn{3}{|c|}{ 15-24 Year Follow-Up } & \multicolumn{3}{|c|}{$\geq 25$ Year Follow-Up } \\
\hline & $\begin{array}{l}\text { Observed } \\
\text { No. of Cases }\end{array}$ & SIR & $95 \% \mathrm{Cl}$ & $\begin{array}{l}\text { Observed } \\
\text { No. of Cases }\end{array}$ & SIR & $95 \% \mathrm{Cl}$ & $\begin{array}{l}\text { Observed } \\
\text { No. of Cases }\end{array}$ & SIR & $95 \% \mathrm{Cl}$ \\
\hline$\leq 20$ & 6 & 20.0 & 7.3 to 43.4 & 19 & 20.8 & 12.6 to 32.6 & 13 & 14.2 & 7.6 to 24.3 \\
\hline $21-30$ & 10 & 5.3 & 2.5 to 9.7 & 20 & 7.3 & 4.5 to 11.3 & 12 & 9.0 & 4.7 to 15.7 \\
\hline $31-40$ & 6 & 1.8 & 0.7 to 3.9 & 8 & 3.2 & 1.4 to 6.3 & 7 & 8.4 & 3.4 to 17.2 \\
\hline $41-50$ & 2 & 0.9 & 0.1 to 3.1 & 3 & 2.0 & 0.4 to 5.9 & 1 & 2.4 & 0.1 to 13.2 \\
\hline
\end{tabular}

Abbreviation: SIR, standardized incidence ratio; IBC, invasive breast cancer. 
Table 4. Effects of Radiation Volume, Gonadotoxic Therapy, Hormone, and Lifestyle Factors on BC Risk (IBC + DCIS) Among Women Irradiated to the Breast Before Age 41 Years*

\begin{tabular}{|c|c|c|c|c|c|c|c|c|}
\hline \multirow[b]{3}{*}{ Characteristic } & \multicolumn{8}{|c|}{ Model } \\
\hline & \multicolumn{2}{|c|}{$1 \dagger$} & \multicolumn{2}{|c|}{$2 \dagger$} & \multicolumn{2}{|c|}{$3 † \ddagger$} & \multicolumn{2}{|c|}{$4 † \ddagger$} \\
\hline & $\mathrm{HR}$ & $95 \% \mathrm{Cl}$ & $\mathrm{HR}$ & $95 \% \mathrm{Cl}$ & $\mathrm{HR}$ & $95 \% \mathrm{Cl}$ & $\mathrm{HR}$ & $95 \% \mathrm{Cl}$ \\
\hline Mediastinal RT & 1 (Ref) & & 1 (Ref) & & 1 (Ref) & & 1 (Ref) & \\
\hline Mantle field & 2.7 & 1.1 to 6.9 & 2.4 & 0.9 to 6.4 & 3.0 & 1.2 to 7.6 & 2.8 & 1.1 to 7.2 \\
\hline Other supradiaphragmatic RT & 0.9 & 0.2 to 4.8 & 0.8 & 0.2 to 4.3 & 1.2 & 0.2 to 6.3 & 1.2 & 0.2 to 6.3 \\
\hline Pelvic RT & 0.4 & 0.1 to 1.4 & 0.4 & 0.1 to 1.3 & & & & \\
\hline No CT/non-alkylating CT & 1 (Ref) & & & & & & & \\
\hline Alkylating $\mathrm{CT}, \leq 8.4 \mathrm{~g} / \mathrm{m}^{2}$ procarbazine & 0.6 & 0.3 to 0.9 & & & & & & \\
\hline Alkylating $\mathrm{CT},>8.4 \mathrm{~g} / \mathrm{m}^{2}$ procarbazine & 0.4 & 0.1 to 1.3 & & & & & & \\
\hline Supradiaphragmatic RT only & & & 1 (Ref) & & & & & \\
\hline Supradiaphragmatic RT + MOPP & & & 0.5 & 0.3 to 0.9 & & & & \\
\hline Supradiaphragmatic $\mathrm{RT}+\mathrm{CT}$, agents unknown & & & 0.7 & 0.2 to 2.3 & & & & \\
\hline \multicolumn{9}{|l|}{ Premature menopause $\|$} \\
\hline Menopause at age 41 or later & & & & & 1 (Ref) & & & \\
\hline Menopause before age 41 & & & & & 0.4 & 0.2 to 0.8 & & \\
\hline Age $\leq 41$ at end of follow-up & & & & & 0.5 & 0.2 to 0.9 & & \\
\hline \multicolumn{9}{|l|}{ Years intact ovarian function\| } \\
\hline$<10$ & & & & & & & 0.3 & 0.2 to 0.6 \\
\hline $10-20$ & & & & & & & 1 (Ref) & \\
\hline$>20$ & & & & & & & 5.3 & 2.9 to 9.9 \\
\hline \multicolumn{9}{|l|}{ Lifestyle factorsף } \\
\hline Smoking (yes $v$ no/unknown) & & & & & 0.9 & 0.6 to 1.6 & 1.0 & 0.6 to 1.6 \\
\hline $\mathrm{BMI}>30$ (yes $v$ no/unknown) & & & & & 1.1 & 0.7 to 1.7 & 1.2 & 0.8 to 1.9 \\
\hline \multicolumn{9}{|l|}{ Hormone factors $\mathbb{I}$} \\
\hline
\end{tabular}

Abbreviations: BC, breast cancer; IBC, invasive breast cancer; DCIS, ductal carcinoma in situ; HR, hazard ratio; RT, radiotherapy; Ref, referent; CT, chemotherapy; MOPP, mechlorethamine, vincristine, procarbazine, and prednisone; ABV, doxorubicine, bleomycine, and vinblastine; BMI, body mass index.

*Because women treated after the age of 40 did not experience an increased risk for BC compared with the general population, we restricted the Cox regression analyses on the effects of radiation volume, gonadotoxic treatment, and other risk factors to women treated before age 41 ( $\mathrm{n}=782$ ).

†Adjusted for each other, age at first RT to the breast, and time since first RT to the breast; calendar time was used as the time scale. Time at risk for RT started 5 years after first treatment with RT.

$\ddagger$ Analysis was restricted to patients from Netherlands Cancer Institute-Antoni van Leeuwenhoek Hospital, Erasmus MC/Daniel den Hoed Kliniek, Leiden University

Medical Center, Emma Children's Hospital/Academic Medical Center ( $n=715$ ).

$\S$ Unknown CT/unknown procarbazine dose was modeled as a separate category. Cumulative treatment was analyzed time dependent; patients may contribute person time to more than one category.

UUnknown age at menopause was modeled as a separate category. Cumulative duration of intact ovarian function was analyzed time dependent; patients may contribute person time to more than one category.

TPrevious experience taught us that when these factors are not mentioned in the medical records (unknown) they are usually not present (no).

Previously, dose-response relationships have been shown for the radiation dose to the area of the breast where the tumor developed, ${ }^{12,13}$ and for tumor dose. ${ }^{32,33}$ We therefore hypothesize that risks for $\mathrm{BC}$ in women treated in recent years (with both smaller volumes and lower doses [20 to $30 \mathrm{~Gy}$ ]) may be even lower than the risks presented. Although it will take at least another decade to study the BC risk associated with modern HL treatments (as the median time from HL treatment to BC was 20 years in our study), future studies assessing the effects of radiation volume and dose at the same time will be very informative.

Recently, two case-control studies investigated the independent and joint effects of RT and CT. ${ }^{12,13}$ It was found that alkylating chem- otherapy decreases the risk of BC among female HL survivors. It is thought that the protective effect of alkylating chemotherapy is mediated through induction of premature menopause, and that hormone stimulation plays an important role in RT-induced breast carcinogenesis. $^{14,15}$ Our results convincingly show that not only premature menopause as such is important, but especially the duration of intact ovarian function after first radiation treatment.

In concordance with this theory, we did not find an increased risk for BC in women treated between ages 41 to 50 . The decreasing $\mathrm{BC}$ risk with older age at irradiation may be explained by the fact that older women have fewer years left before natural menopause. The absence of an increased risk of BC in women treated between 


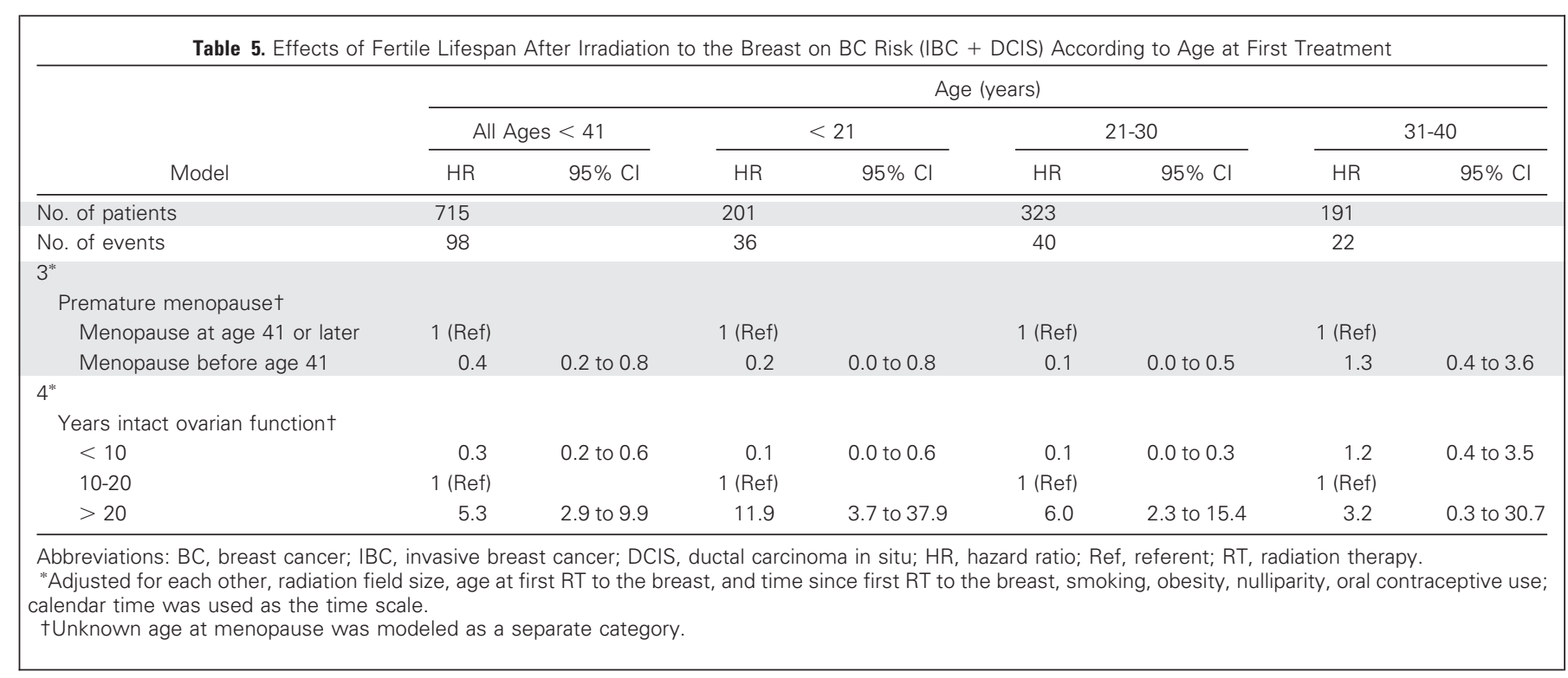

ages 41 to 50 may also be explained by potential lack of power resulting from a sharp rise in expected cases of breast cancer in this group of women.

No significant difference was found between women treated between ages 31 to 40 with at least 10 years of intact ovarian function compared with those who became postmenopausal within the first 10 years after treatment. One may argue that taking cutoff points of 10 and 20 years of intact ovarian function in a group of women treated between age 31 and 40 results in too little contrast, because these women are close to the age at which natural menopause occurs. However, comparing women with fewer than 2 years of intact ovarian function after treatment to those with 5 to 10 years of intact ovarian function in this age group, no significant difference was observed (HR, 0.6 ; $95 \%$ CI, 0.1 to 3.1 ), although this estimate was based on a small group of women.

In concordance with previous studies among survivors of childhood and adolescent HL, ${ }^{8,17}$ we did not find a protective effect of alkylating CT or pelvic RT as such on the risk of radiation-induced BC in women treated before age 21 . However, we did find a strong association between cumulative years with intact ovarian function and future risk of $\mathrm{BC}$ after irradiation. Those with the longest duration of intact ovarian function after treatment, and therefore a relatively normal fertile life span, experienced a much larger risk of BC compared with those entering premature menopause relatively shortly after treatment.

In contrast to previous findings, ${ }^{11}$ we found that the SIRs for women treated between ages 31 to 40 significantly increased over time. The increased risk with prolonged follow-up may have been caused by the fact that, until recently, women irradiated after the age of 30 were not regularly screened for breast cancer in the Netherlands.

When interpreting the results of this study, certain limitations should be taken into account. It has been hypothesized that the protective effect of endogenous hormone ablation may be diminished by exposure to exogenous hormones. ${ }^{13-15}$ Timing and type of exogenous hormone exposure as well as dose and duration are crucial in analyses regarding this subject. Unfortunately, adequate evaluation of this topic was not possible in our present study, since data on oral contraceptive use and HRT were only available at the yes/no level. Furthermore, the prevalence of HRT use in the Netherlands is relatively low. ${ }^{13}$ Other potential weaknesses of our study are the previously discussed inability to assess radiation dose effects and some missing data regarding age at menopause.

In summary, women treated with RT for HL before the age of 41 experience a high risk for $\mathrm{BC}$. Our results show that reduction of radiation volume can lower this risk. Gonadotoxic treatment can also reduce the future risk for $\mathrm{BC}$, especially when menopause occurs relatively shortly after treatment. The beneficial effect of gonadotoxic treatment is present in women treated before age 31 . Women treated between age 31 and 40 do experience an increased risk for BC, but this risk is not reduced by gonadotoxic treatment, possibly because there are fewer years before natural menopause occurs in these patients. When confirmed by others, these findings may have implications for BC screening in female HL survivors.

\section{AUTHORS' DISCLOSURES OF POTENTIAL CONFLICTS OF INTEREST}

The author(s) indicated no potential conflicts of interest.

\section{AUTHOR CONTRIBUTIONS}

Conception and design: Marie L. De Bruin, Judith Sparidans, Berthe M.P. Aleman, Flora E. van Leeuwen

Administrative support: Marie L. De Bruin, Mars B. van't Veer, Evert M. Noordijk, Flora E. van Leeuwen

Provision of study materials or patients: Mars B. van't Veer, Evert M. Noordijk, Marieke W.J. Louwman, Josée M. Zijlstra, Hendrik van den Berg, Nicola S. Russell, Margreet H.A. Baaijens

Collection and assembly of data: Marie L. De Bruin, Judith Sparidans, Josée M. Zijlstra, Nicola S. Russell, Annegien Broeks 
Data analysis and interpretation: Marie L. De Bruin, Judith Sparidans, Berthe M.P. Aleman, Flora E. van Leeuwen

Manuscript writing: Marie L. De Bruin, Judith Sparidans, Berthe M.P. Aleman, Flora E. van Leeuwen
Final approval of manuscript: Marie L. De Bruin, Judith Sparidans, Mars B. van't Veer, Evert M. Noordijk, Marieke W.J. Louwman, Josée M. Zijlstra, Hendrik van den Berg, Nicola S. Russell, Annegien Broeks, Margreet H.A. Baaijens, Berthe M.P. Aleman, Flora E. van Leeuwen

\section{REFERENCES}

1. Donaldson SS, Hancock SL: Second cancers after Hodgkin's disease in childhood. N Engl J Med 334:792-794, 1996

2. Dores GM, Metayer C, Curtis RE, et al: Second malignant neoplasms among long-term survivors of Hodgkin's disease: A population-based evaluation over 25 years. J Clin Oncol 20:3484-3494, 2002

3. Goss PE, Sierra S: Current perspectives on radiation-induced breast cancer. J Clin Oncol 16: 338-347, 1998

4. Neglia JP, Friedman DL, Yasui Y, et al: Second malignant neoplasms in five-year survivors of childhood cancer: Childhood cancer survivor study. J Nat Cancer Inst 93:618-629, 2001

5. van Leeuwen FE, Klokman WJ, Veer MB, et al: Long-term risk of second malignancy in survivors of Hodgkin's disease treated during adolescence or young adulthood. J Clin Oncol 18:487-497, 2000

6. Wolden SL, Hancock SL, Carlson RW, et al Management of breast cancer after Hodgkin's disease. J Clin Oncol 18:765-772, 2000

7. Wolf J, Schellong G, Diehl V: Breast cancer following treatment of Hodgkin's disease: More reasons for less radiotherapy? Eur J Cancer 33: 2293-2294, 1997

8. Bhatia $S$, Yasui $Y$, Robison $L L$, et al: High risk of subsequent neoplasms continues with extended follow-up of childhood Hodgkin's disease: Report from the Late Effects Study Group. J Clin Oncol 21:4386-4394, 2003

9. Sankila R, Garwicz S, Olsen JH, et al: Risk of subsequent malignant neoplasms among 1,641 Hodgkin's disease patients diagnosed in childhood and adolescence: A population-based cohort study in the five Nordic countries: Association of the Nordic Cancer Registries and the Nordic Society of Pediatric Hematology and Oncology. J Clin Oncol 14:1442-1446, 1996

10. Swerdlow AJ, Barber JA, Hudson GV, et al: Risk of second malignancy after Hodgkin's disease in a collaborative British cohort: The relation to age at treatment. J Clin Oncol 18:498-509, 2000

11. Hodgson DC, Gilbert ES, Dores GM, et al: Long-term solid cancer risk among 5-year survivors of Hodgkin's lymphoma. J Clin Oncol 25:1489-1497, 2007

12. Travis LB, Hill DA, Dores GM, et al: Breast cancer following radiotherapy and chemotherapy among young women with Hodgkin disease. JAMA 290:465-475, 2003

13. van Leeuwen FE, Klokman WJ, Stovall M, et al: Roles of radiation dose, chemotherapy, and hormonal factors in breast cancer following Hodgkin's disease. J Natl Cancer Inst 95:971-980, 2003

14. Horwich A, Swerdlow AJ: Second primary breast cancer after Hodgkin's disease. Br J Cancer 90:294-298, 2004

15. Yahalom J: Breast cancer after Hodgkin disease: Hope for a safer cure. JAMA 290:529-531, 2003

16. Franklin J, Pluetschow $A$, Paus $M$, et al: Second malignancy risk associated with treatment of Hodgkin's lymphoma: Meta-analysis of the randomised trials. Ann Oncol 17:1749-1760, 2006

17. Kenney LB, Yasui $Y$, Inskip PD, et al: Breast cancer after childhood cancer: A report from the Childhood Cancer Survivor Study. Ann Intern Med 141:590-597, 2004

18. Aleman $B M$, van den Belt-Dusebout AW, Klokman WJ, et al: Long-term cause-specific mortality of patients treated for Hodgkin's disease. J Clin Oncol 21:3431-3439, 2003

19. van Leeuwen FE, Klokman WJ, Hagenbeek A, et al: Second cancer risk following Hodgkin's disease: A 20-year follow-up study. J Clin Oncol 12: 312-325, 1994

20. Aleman BM, van den Belt-Dusebout AW, De Bruin $\mathrm{ML}$, et al: Late cardiotoxicity after treatment for Hodgkin lymphoma. Blood 109:1878-1886, 2007

21. De Bruin ML, Huisbrink J, Hauptmann M, et al: Treatment-related risk factors for premature menopause following Hodgkin lymphoma. Blood 111:101-108, 2008
22. Eghbali H, Raemaekers J, Carde P: The EORTC strategy in the treatment of Hodgkin's lymphoma. Eur J Haematol Suppl 66:135-140, 2005

23. Connors JM, Noordijk EM, Horning SJ: Hodgkin's lymphoma: Basing the treatment on the evidence. Hematology Am Soc Hematol Educ Program 178-193, 2001

24. Raemaekers J, Kluin-Nelemans $\mathrm{H}$, Teodorovic I, et al: The achievements of the EORTC Lymphoma Group: European Organisation for Research and Treatment of Cancer. Eur J Cancer 38:S107-S113 (suppl 4), 2002

25. Gooley TA, Leisenring W, Crowley J, et al: Estimation of failure probabilities in the presence of competing risks: New representations of old estimators. Stat Med 18:695-706, 1999

26. Kaplan EL, Meier P. Nonparametric estimation from incomplete observations. J Am Stat Assoc 53:457-481, 1958

27. Louwman WJ, Voogd AC, van Dijck JA, et al: On the rising trends of incidence and prognosis for breast cancer patients diagnosed 1975-2004: A long-term population-based study in southeastern Netherlands. Cancer Causes Control 19:97-106, 2008

28. The Netherlands Cancer Registry: Cancer in figures. Utrecht, the Netherlands, Association of Comprehensive Cancer Centres. www.ikcnet.n

29. Therneau T, Offord J: Expected survival based on hazard rates (update): Technical Report No. 63. Rochester, MN, Mayo Clinic Section of Biostatistics, 1999

30. Cox DR, Oakes D: Analysis of survival data. New York, NY, CRC Press, 1984

31. Korn EL, Graubard BI, Midthune D: Time-toevent analysis of longitudinal follow-up of a survey: Choice of the time-scale. Am J Epidemiol 145:72-80, 1997

32. Bhatia S, Robison LL, Oberlin O, et al: Breast cancer and other second neoplasms after childhood Hodgkin's disease. N Engl J Med 334:745-751, 1996

33. Tinger $A$, Wasserman $T H$, Klein $E E$, et al: The incidence of breast cancer following mantle field radiation therapy as a function of dose and technique. Int J Radiat Oncol Biol Phys 37:865-870, 1997 